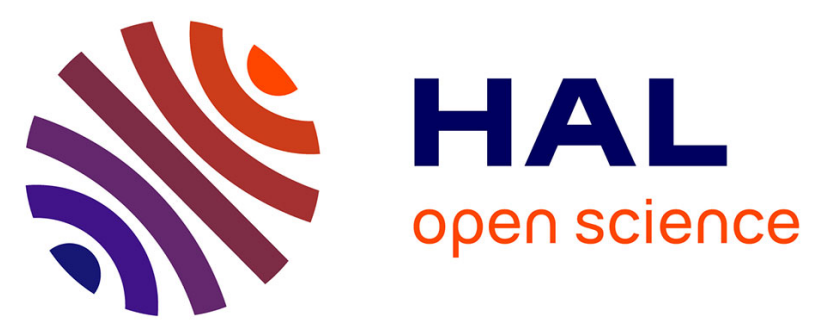

\title{
Kinetic study of isobutyric acid oxydehydrogenation on various FePO catalysts. Proposal for the reaction mechanism
}

Christine Virely, Michel Forissier, Jean-Marc Millet, Jacques Vedrine, Dominique Huchette

\section{To cite this version:}

Christine Virely, Michel Forissier, Jean-Marc Millet, Jacques Vedrine, Dominique Huchette. Kinetic study of isobutyric acid oxydehydrogenation on various FePO catalysts. Proposal for the reaction mechanism. Journal of Molecular Catalysis, 1992, 71, pp.199-213. 10.1016/0304-5102(92)80018-C . hal-00006299

\section{HAL Id: hal-00006299 \\ https://hal.science/hal-00006299}

Submitted on 25 Jan 2022

HAL is a multi-disciplinary open access archive for the deposit and dissemination of scientific research documents, whether they are published or not. The documents may come from teaching and research institutions in France or abroad, or from public or private research centers.
L'archive ouverte pluridisciplinaire HAL, est destinée au dépôt et à la diffusion de documents scientifiques de niveau recherche, publiés ou non, émanant des établissements d'enseignement et de recherche français ou étrangers, des laboratoires publics ou privés.

\section{(c) (1) $\$$}

Distributed under a Creative Commons Attribution - NonCommerciall 4.0 International 


\title{
Kinetic study of isobutyric acid oxydehydrogenation on various $\mathrm{Fe}-\mathrm{P}-\mathrm{O}$ catalysts: proposal for the reaction mechanism
}

\author{
Christine Virely, Michel Forissier*, Jean-Marc M. Millet**, \\ Jacques C. Védrine \\ Institut de Recherches sur la Catalyse, CNRS, associé à l'Université Claude Bernard, \\ Lyon I, 2 Av. Albert Einstein, 69626 Villeurbanne, Cédex (France)
}

and Dominique Huchette

Centre de Recherches du Nord, ORKEM, 62670 Mazingarbe (France)

\begin{abstract}
A mechanism and rate expressions are proposed to explain the conversion kinetics of isobutyric acid to methacrylic acid by oxidative dehydrogenation on several iron phosphate catalysts. The relation between the catalyst nature and rate constants led us to suggest improvements in the catalysts and in reaction conditions. The mechanism proposed involves surface hydroxyl groups and sites composed of two nearby Fe cations. It corresponds to a new extension of the well-known Mars and Van Krevelen mechanism, often postulated for partial oxidation reactions on oxides.
\end{abstract}

\section{Introduction}

Methyl methacrylate is an essential monomer in the manufacture of plastic resins and fibers. Alternative processes to produce this monomer are studied today all over the world. Among them, an attractive one involves the esterification of methacrylic acid produced by oxydehydrogenation of isobutyric acid obtained by hydroformylation of propene.

Two types of catalyst have been proposed for isobutyric acid oxidative dehydrogenation: iron phosphates [1,2] and heteropolyanions [3-5]. Few studies on iron phosphates have been published thus far except in the patent literature. We have therefore undertaken to study in more detail the oxydehydrogenation reaction of isobutyric acid on $\mathrm{Fe}-\mathrm{P}-\mathrm{O}$ catalysts.

The ternary system $\mathrm{Fe}_{2} \mathrm{O}_{3}-\mathrm{FeO}-\mathrm{P}_{2} \mathrm{O}_{5}$ has recently been studied [6, 7]. It exhibits different phases which contain both ferric and ferrous ions, suggesting possible utilisation for partial oxidation reactions involving a redox mechanism. New phases such as $\mathrm{Fe}_{3}\left(\mathrm{PO}_{4}\right) \mathrm{O}_{3}, \mathrm{Fe}_{4}\left(\mathrm{PO}_{4}\right)_{2} \mathrm{O}, \mathrm{Fe}_{9}\left(\mathrm{PO}_{4}\right) \mathrm{O}_{8}$ and

*Present address: Laboratoire de Génie Catalytique des Réacteurs de Raffinage. CRES, BP 22, 69360, Saint Symphorien d'Ozon, France.

**Author to whom correspondence should be addressed. 
$\mathrm{Fe}_{2}\left(\mathrm{PO}_{4}\right) \mathrm{O}$ have been characterized [8-12] and some of them have been studied as catalysts in the oxidation of propene [13]. In this reaction, phosphates and oxyphosphates exhibit the usual properties of oxidation catalysts and can activate oxygen. Important differences in catalytical properties have been related to the crystallographic structures [13]. A recent study of various phosphates in the conversion of ethylbenzene to styrene [14] has shown that these solids could act as oxydehydrogenating catalysts, but the proposed mechanism, which suggests a phosphate ester and a phenethanol as intermediates, involves essentially the acidic properties of the catalyst [14]. However the data presented here strongly suggest that the redox properties of the catalyst play an important role that must be taken into account, as is usual for partial oxidation reactions. A recent paper shows also that $\mathrm{FePO}$ catalysts may be used for the oxidative coupling of methane at a relatively low temperature $\left(575^{\circ} \mathrm{C}\right)[15]$.

A complete kinetic study of the catalytic oxydehydrogenation of isobutyric acid on various phosphates would be useful to obtain information on the mechanism of the reaction and to determine which characteristics of the catalyst are needed to increase the yield of methacrylic acid. Our first results in this attempt have shown the important role of added water vapour pressure [16] and the important effect of the nature of the solid on the catalytic properties, while the evolution of the catalyst crystalline structure during the reaction has also been evidenced [17].

\section{Experimental}

\section{Catalyst preparation}

Different pure and well-characterized solids were prepared. Their compositions are given in Table 1 and their position in the phase diagram $\mathrm{Fe}_{2} \mathrm{O}_{3}-\mathrm{FeO}-\mathrm{P}_{2} \mathrm{O}_{5}$ shown in Fig. 1. $\mathrm{FePO}_{4}$ has been prepared by firing at 973

\section{TABLE 1}

Physicochemical characteristics of the tested compounds

\begin{tabular}{lllll}
\hline Compound & $\begin{array}{l}\text { Specific } \\
\text { Surface area (BET) } \\
\left(\mathrm{m}^{2} \mathrm{~g}^{-1}\right)\end{array}$ & $\frac{\mathrm{Fe}^{3+}}{\mathrm{Fe}^{2+}+\mathrm{Fe}^{3+}}$ & $R=\frac{\mathrm{O}-\mathrm{Fe}}{\mathrm{O}-\mathrm{Fe}+\mathrm{O}-\mathrm{P}}$ & $\begin{array}{l}\mathrm{Fe} / \mathrm{P} \\
\text { Atomic ratio }\end{array}$ \\
\hline $\mathrm{Fe}_{2} \mathrm{PO}_{5} \mathrm{a}$ & 0.12 & 0.5 & 0.2 & 2 \\
$\mathrm{Fe}_{2} \mathrm{PO}_{5} \mathrm{~b}$ & 4.10 & 0.5 & 0.2 & 2 \\
$\mathrm{Fe}_{5} \mathrm{P}_{3} \mathrm{O}_{15}$ & 25.50 & 1.0 & 0.2 & 1.67 \\
$\mathrm{Fe}_{7}\left(\mathrm{PO}_{4}\right)_{8}$ & 0.42 & 0.57 & 0.0 & 1 \\
$\mathrm{FePO}_{4}$ & 0.94 & 1.0 & 0.0 & 1 \\
$\mathrm{Fe}_{2} \mathrm{P}_{2} \mathrm{O}_{7}$ & 3.80 & 0.0 & 0.0 & $b$ \\
Ind.Cat. & 2.50 & 1.0 & $b$ & \\
\hline
\end{tabular}

${ }^{R} R=$ ratio of the number of $\mathrm{O}-\mathrm{Fe}$ bonds to the total number of $\mathrm{O}$ bonds.

Data not given (see [18]). 


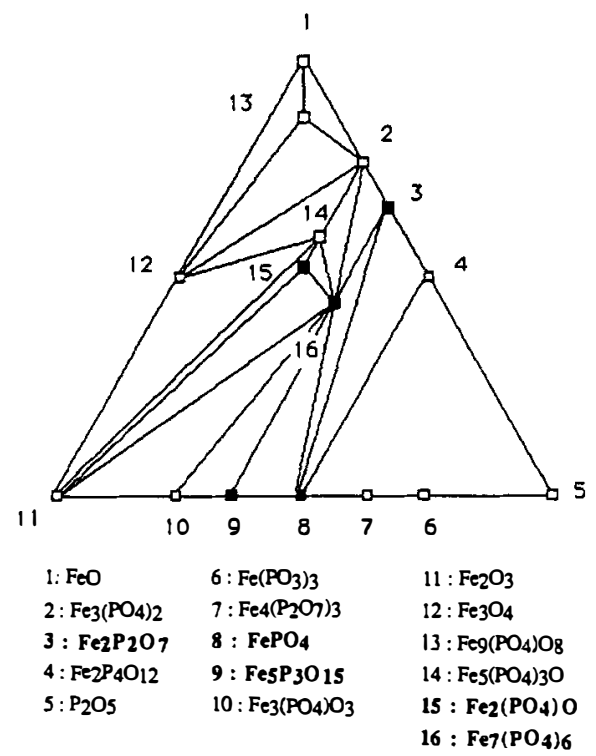

Fig. 1. $\mathrm{Fe}-\mathrm{P}-\mathrm{O}$ low temperature partial phase diagram (673-873 $\mathrm{K})$. Tested compounds are written in bold.

$\mathrm{K}$ appropriate mixtures of $\mathrm{Fe}_{2} \mathrm{O}_{3}$ and $\mathrm{H}_{2}\left(\mathrm{NH}_{4}\right) \mathrm{PO}_{4}$. Special heat treatments under vacuum or $\mathrm{H}_{2} \mathrm{O}-\mathrm{H}_{2}-\mathrm{N}_{2}$ gas mixtures were necessary to prepare the other mixed-valence phosphates [7-9]. An industrial type catalyst containing an alkaline element in addition to $\mathrm{Fe}$ and $\mathrm{P}$, has been supplied by ORKEM and will be referred to as 'ind. cat.' [18].

Purity and crystallinity of the samples were checked by chemical analysis and X-Ray diffraction. B.E.T. surface area measurements were performed on a volumetric apparatus by adsorption of nitrogen at liquid nitrogen temperature.

\section{Kinetic study}

A special device was built for this study as described in [16]. The main difficulty was to avoid the polymerization of methacrylic acid. The online analysis of $\mathrm{O}_{2}, \mathrm{~N}_{2}, \mathrm{CO}, \mathrm{CO}_{2}, \mathrm{H}_{2} \mathrm{O}$, propene, acetone and acetic, propenoic, methacrylic and isobutyric acids allowed control of the mass blance. The device could be used as a differential flow reactor (low conversion) to study the effect of $\mathrm{O}_{2}$, isobutyric acid (IBA) and water relative partial pressures on the reaction rate at the steady state of the reaction. It could also be used as an integral flow reactor to obtain an important conversion and to measure selectivity $v s$. conversion at a constant temperature. The degradation of the reaction products could be measured without drastically increasing the conversion, but only by adding these products at the reactor inlet. In the range of reaction conditions investigated, methacrylic acid (MAA), acetone, propene and $\mathrm{CO}_{2}$ were found as reaction products over all investigated catalysts. 
After the steady state of the reaction was reached, the isobutyric acid flow was stopped to observe the decrease with time of the partial pressure of this acid and of the reaction products. By comparison with a blank reaction obtained without catalyst, it was possible to estimate the quantities retained on the catalyst. In the same way, by stopping the oxygen flow, it was possible to estimate the amount of lattice or adsorbed oxygen consumed by the reactant molecules.

\section{Results}

\section{Steady state kinetics}

The activity of the various catalysts was stable with time on stream for several days. Only $\mathrm{Fe}_{5} \mathrm{P}_{3} \mathrm{O}_{15}$ exhibited a low and regular selectivity decrease with time (about 6\% per day).

The variations in conversion vs. contact time were plotted and are presented in Fig. 2. The linear part of the curve indicates that the reaction rate is chemically controlled and that the effect of product pressures is not very important, at least when the conversion is lower than $30 \%$, and has been neglected.

The influence of oxygen and isobutyric acid partial pressures on the reaction rate at low conversion $(<10 \%)$ is shown in Fig. 3. The shapes of these curves are compatible with a redox or steady state mechanism [20], except that corresponding to $\mathrm{Fe}_{2} \mathrm{PO}_{5} \mathrm{a}$, which does not allow elimination in this case of the hypothesis of adsorption of isobutyric acid.

The variation of the partial pressure of water in the investigation range $(0-77 \mathrm{kPa})$ has practically no influence on the selectivities. Only a small increase in the selectivities in $\mathrm{CO}_{2}$ (from $5 \%$ to $10 \%$ ) are observed at very low water partial pressure.

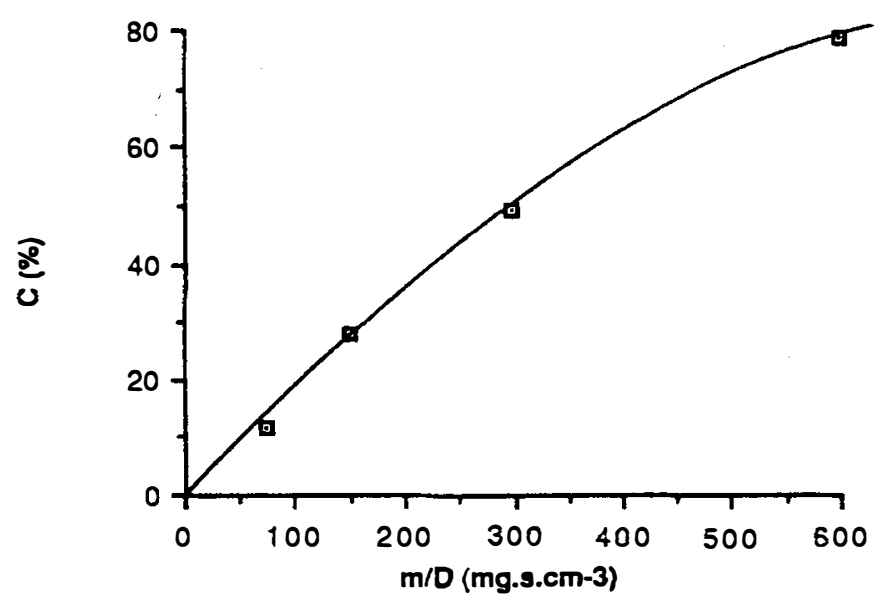

Fig. 2. IBA conversion on industrial catalyst $(\%) v s$. contact time (ratio of catalyst mass to total flow rate in $\mathrm{mg} \mathrm{s} \mathrm{cm} \mathrm{cm}^{-3}$. Temperature $683 \mathrm{~K}$, total flow rate $1 \mathrm{~cm}^{3} \mathrm{~s}^{-1}$, partial pressure ratio $\mathrm{O}_{2} / \mathrm{IBA} / \mathrm{H}_{2} \mathrm{O}=32 / 44 / 570$. 


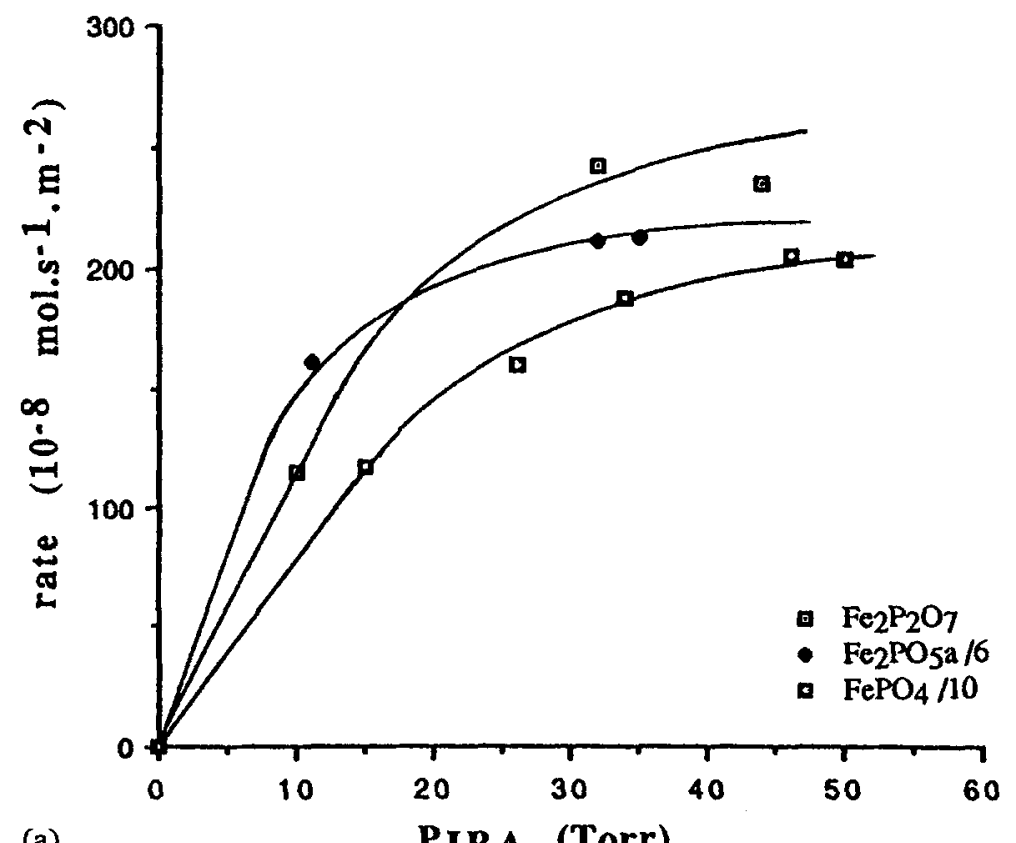

(a) PIBA (Torr)

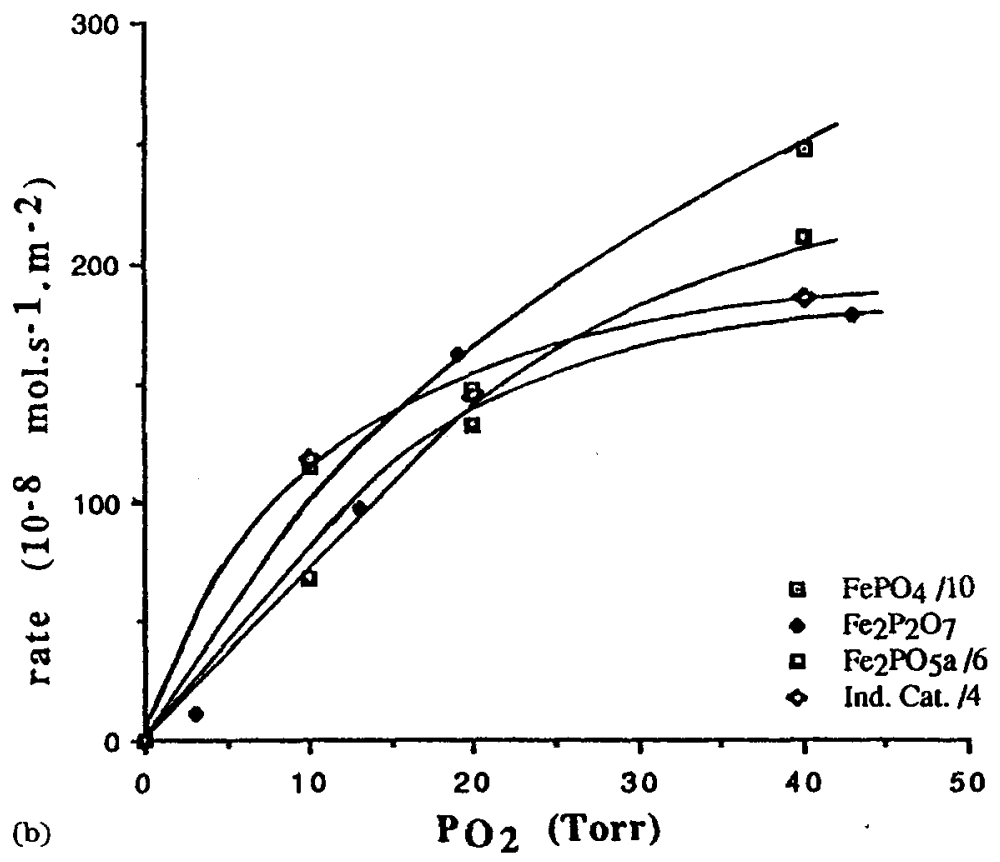

Fig. 3. (a) Isobutyric acid conversion rate in $10^{-8} \mathrm{~mol} \mathrm{~s}^{-1} \mathrm{~m}^{-2}$ vs. isobutyric acid partial pressure in torr ( 1 torr $=0.133 \mathrm{kPa}$ ). Reaction conditions: $658 \mathrm{~K}$, total flow rate $1 \mathrm{~cm}^{3} \mathrm{~s}^{-1}$, oxygen partial pressure 40 torr, water partial vapour pressure 570 torr. (b) Isobutyric acid conversion rate in $10^{-8} \mathrm{~mol} \mathrm{~s}^{-1} \mathrm{~m}^{-2}$ vs. oxygen partial pressure in torr $(1$ torr $=0.133 \mathrm{kPa})$. Reaction conditions: $658 \mathrm{~K}$, total flow rate $1 \mathrm{~cm}^{3} \mathrm{~s}^{-1}$, isobutyric acid partial pressure 35 torr, water partial vapour pressure 570 torr. 
The effect of the water pressure on the rate of formation of the MAA is much greater (Fig. 4). For each solid tested a different maximum reaction rate was observed. This maximum of the rate with water pressure seems to depend on the catalyst and suggests two effects of water pressure. At low pressure the rate increased, i.e. water has a catalytic effect. For higher pressures, the rate decreased. As water is a reaction product, it is possible that it intervenes in an equilibrium step or in a reverse reaction step.

The effect of temperature on the reaction rate is traditionally expressed by an apparent activation energy (Table 2). The values obtained depend on the catalysts. Some very low values, particularly in the acetone formation, suggest an equilibrium step (possibly adsorption) in the acetone formation route. In this case the $\Delta H_{0}$ value of the equilibrium could add to the activation energy to give a low apparent activation energy value.

\section{Transient kinetics}

Hydrocarbon

The variations of the product pressures with time on stream for three solids $\left(\mathrm{Fe}_{2} \mathrm{P}_{2} \mathrm{O}_{7}, \mathrm{Fe}_{7}\left(\mathrm{PO}_{4}\right)_{6}\right.$ and the industrial catalyst), after the isobutyric acid feed was stopped at $t=0$, are shown in Fig. 5. The isobutyric acid relative pressure does not fall immediately, showing that a retention of this

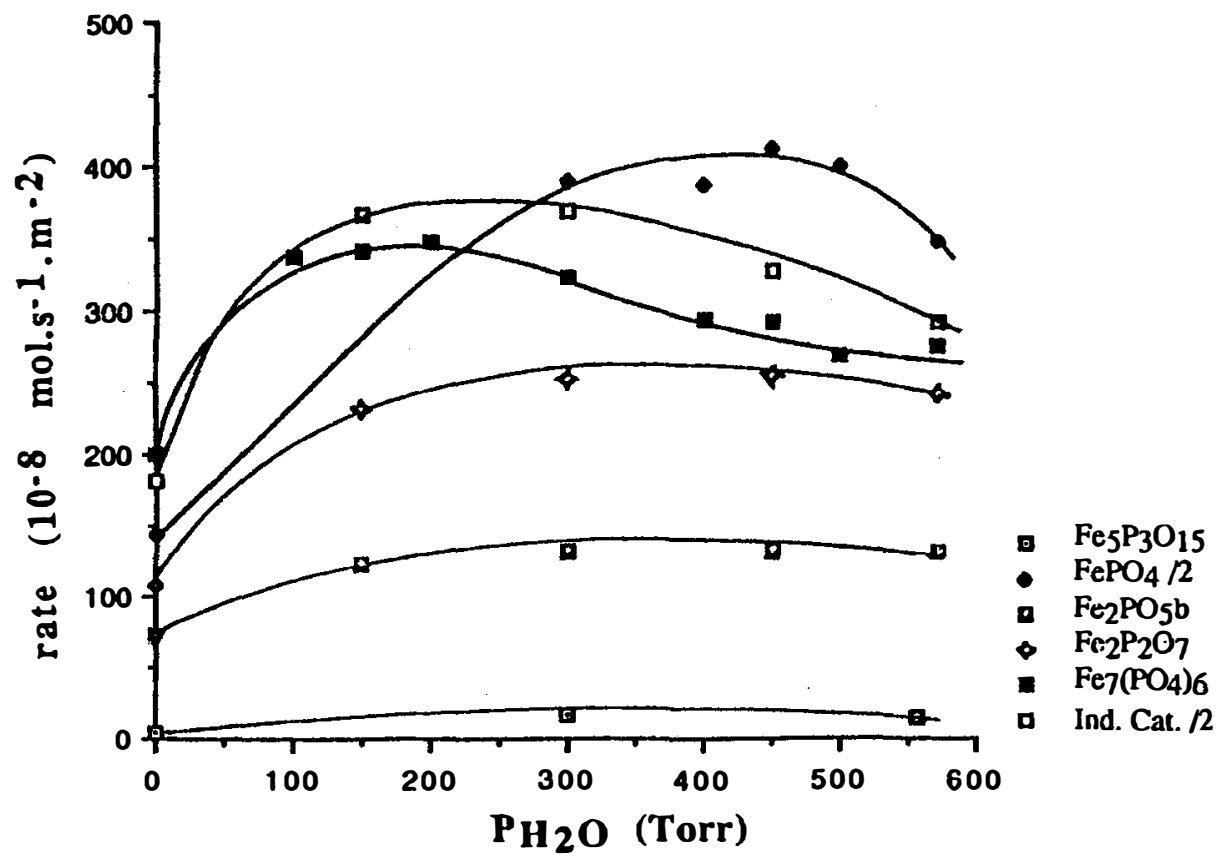

Fig. 4. Rate of methacrylic acid formation in $10^{-8} \mathrm{~mol} \mathrm{~s}^{-1} \mathrm{~m}^{-2}$ vs. water vapour pressure in torr ( 1 torr: $0.133 \mathrm{kPa}$ ). Reactant mixture conditions: $658 \mathrm{~K}, 1 \mathrm{~cm}^{3} \mathrm{~s}^{-1}$, oxygen partial pressure 40 torr, isobutyric acid partial pressure 35 torr. 
reactant on the catalyst has occurred. This observation is compatible with an absorption of this acid on the catalyst. For all the solids, propene, acetone and methacrylic acid relative pressures decreased rapidly below the detection limit except for $\mathrm{Fe}_{2} \mathrm{P}_{2} \mathrm{O}_{7}$, with which an unexpected increase in propene was observed. The decrease in propene and acetone formation occurred more rapidly than that of isobutyric and methacrylic acids, suggesting that intermediate stabilities are lower for propene or acetone. Isobutyric acid adsorption in molecular form is not excluded. In this case the adsorption sites could be different from the active sites.

The integration of areas under the methacrylic acid curves give an estimate of the sum of methacrylic acid adsorption, intermediate adsorption, and the quantities of isobutyric acid adsorbed which could react before desorbing. The latter quantity is important and approaches the equivalent of the complete monolayer of the catalyst surface (Table 3, column 2). An important intermediate concentration on the solid surface is thus evidenced.

TABLE 2

Apparent activation energy values (AAE) $\left(\mathrm{kJ} \mathrm{mol}^{-1} \pm 5\right)$ and selectivity $(S)(\%)$ for reaction products in isobutyric acid oxidative dehydrogenation at $673 \mathrm{~K}$

\begin{tabular}{|c|c|c|c|c|c|c|c|c|}
\hline \multirow[t]{3}{*}{ Sample } & \multicolumn{8}{|c|}{ Reaction products } \\
\hline & \multicolumn{2}{|l|}{$\mathrm{CO}_{2}$} & \multicolumn{2}{|c|}{ Propene } & \multicolumn{2}{|c|}{ Acetone } & \multicolumn{2}{|l|}{ MAA } \\
\hline & AAE & $\mathbf{S}$ & AAE & $\mathbf{S}$ & AAE & $\mathbf{S}$ & AAE & $\mathbf{S}$ \\
\hline $\mathrm{FePO}_{4}$ & 59 & 13 & 79 & 16 & 17 & 70 & 25 & 0 \\
\hline $\mathrm{Fe}_{5} \mathrm{P}_{3} \mathrm{O}_{15}$ & 33 & 11 & 100 & 8 & 0 & 30 & 134 & 50 \\
\hline $\mathrm{Fe}_{7}\left(\mathrm{PO}_{4}\right)_{6}$ & 142 & 9 & 88 & 7 & 38 & 53 & 176 & 32 \\
\hline $\mathrm{Fe}_{2} \mathrm{PO}_{5} \mathrm{a}$ & 71 & 13 & nd & nd & 69 & 88 & nd & nd \\
\hline $\mathrm{Fe}_{2} \mathrm{PO}_{5} \mathrm{~b}$ & 25 & 22 & 92 & $\epsilon$ & 17 & 47 & 63 & 31 \\
\hline $\mathrm{Fe}_{2} \mathrm{P}_{2} \mathrm{O}_{7}$ & 130 & 11 & 125 & 10 & 17 & 39 & 100 & 39 \\
\hline Ind. cat. & 71 & 2 & 63 & 9 & 0 & 19 & 84 & 70 \\
\hline
\end{tabular}

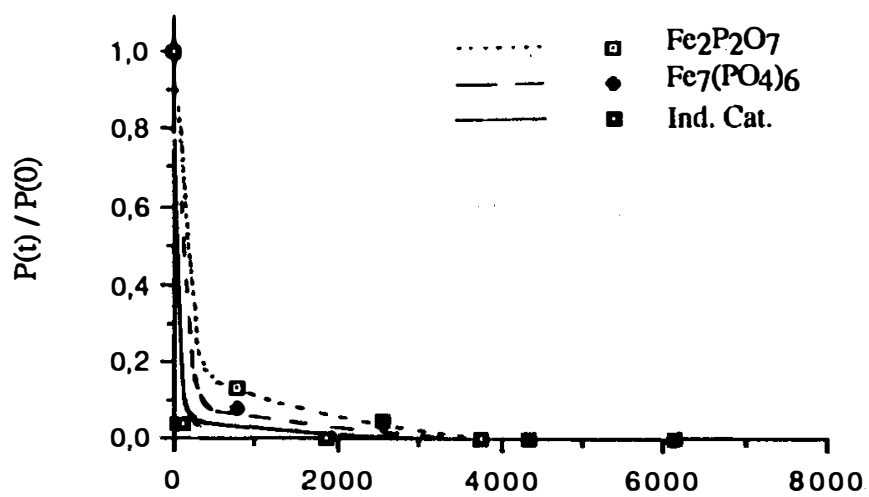

Fig. 5. (a) 

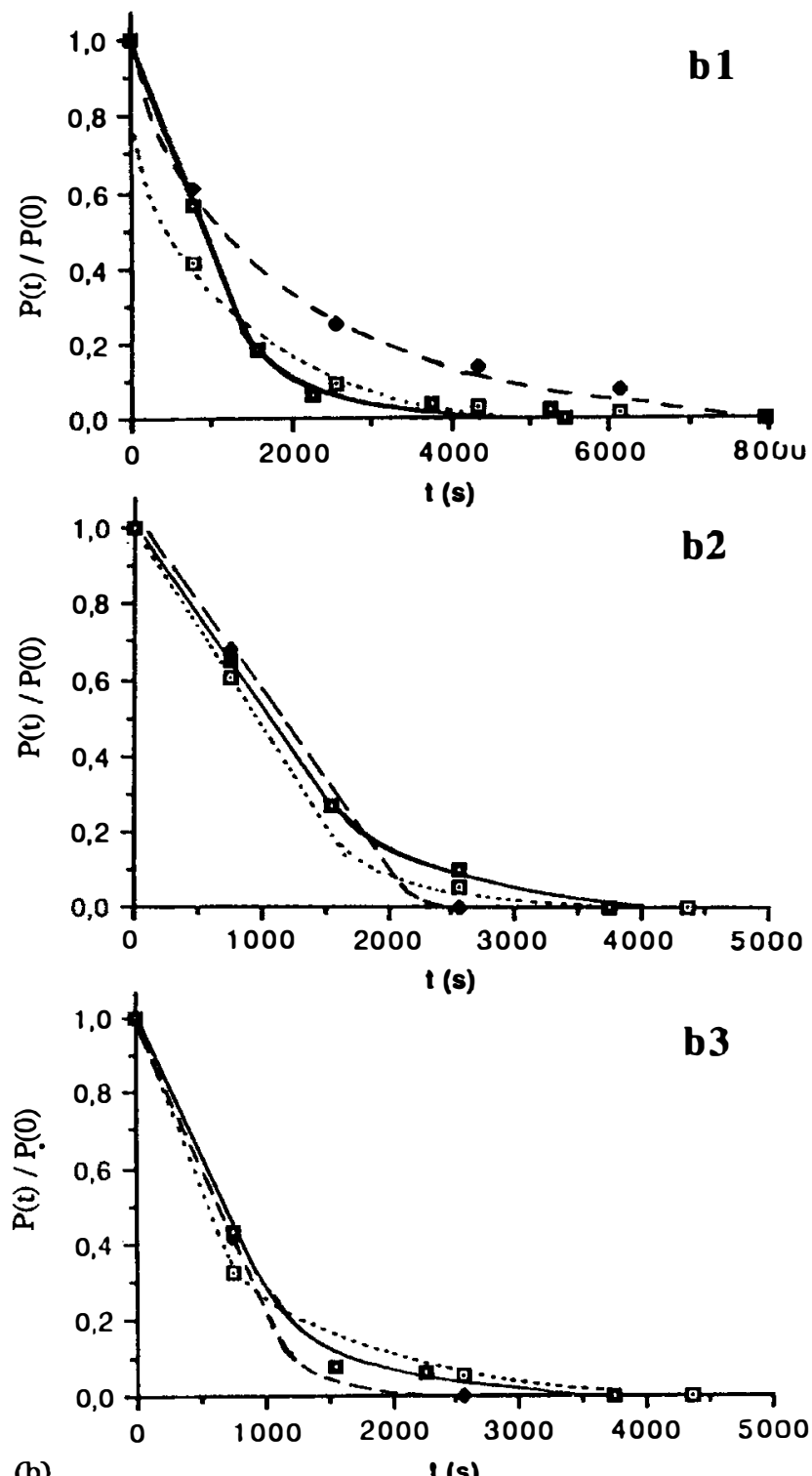

(b)

I (s)

Fig. 5. (b) Transient kinetics. Evolution of relative pressures versus time (in s). The sample was equilibrated to steady state in conditions given in Fig. 2. (a) after reducing isobutyric acid flow rate. (b) after reducing oxygen flow rate; evolution of MAA $\left(b_{1}\right)$, propene $\left(b_{2}\right)$ and acetone $\left(b_{3}\right)$.

\section{Oxygen}

The evolution of the relative pressure of products after stopping the oxygen and water flows is shown in Fig. $5 \mathrm{~b}$. It can be seen that the decreases in these pressures are slower than those observed after stopping isobutyric 
TABLE 3

Estimated values of superficial concentration from transient kinetics at $673 \mathrm{~K}, P_{\mathrm{IBA}}=5.26 \mathrm{kPa}$, $P_{\mathrm{O} 2}=5.26 \mathrm{kPa}, P_{\mathrm{H} 2 \mathrm{O}}=75 \mathrm{kPa}$

\begin{tabular}{lllc}
\hline Sample & $\begin{array}{l}\text { Superficial concentration } \\
\text { of adsorbed IBA } \\
\left(\mathrm{mmol} \mathrm{m}^{-2}\right)\end{array}$ & \multicolumn{2}{l}{ Removable oxygen } \\
\cline { 3 - 4 } & & $(w \mathrm{t} . \%)$ & $\begin{array}{l}\text { Number of } \\
\text { atomic layers }\end{array}$ \\
\hline $\mathrm{Fe}_{7}\left(\mathrm{PO}_{4}\right)_{6}$ & 24 & 12 & 340 \\
$\mathrm{Fe}_{2} \mathrm{P}_{2} \mathrm{O}_{7}$ & 3 & 24 & 70 \\
Ind. cat. & 0.3 & 12 & 60 \\
\hline
\end{tabular}

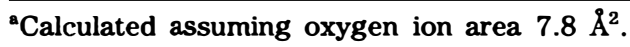

acid feed. This indicates that the solids are able to release a very large amount of oxygen (Table 3 , column 3 ), i.e. that lattice oxygen intervenes in the reaction, as is usually observed in partial oxidation catalysis, even from the bulk.

Acetone formation decreases more rapidly than those of the other products after oxygen flow stops, showing that oxygen sites for this product are the most easily reduced. Propene formation decreases more slowly and thus is less affected by the surface reduction. Note that propene and acetone formation stopped while that of methacrylic acid continued. These observations show that propene, methacrylic acid and acetone are probably formed on different sites.

\section{Kinetic model}

Kinetic expression

The various observations described above suggest that the catalyst works as an oxidation catalyst via the well-known Mars and Van Krevelen steady state mechanism [21]. The amount of oxygen that could be removed from the solid is high, i.e. the catalyst could be deeply reduced [20]. Let us recall that a Mars and Van Krevelen type mechanism was also found in isobutyric acid oxydehydrogenation on heteropolyanions [5].

However the Mars and Van Krevelen mechanism does not take into account the retention of adsorbed isobutyric acid and the effect of water partial pressure. The increase in the rate with increasing water vapour pressure suggests that water creates active sites. On the oxide surface, water is expected to form hydroxyl groups, thus the effect of water and oxygen partial pressures suggests that active sites of the catalyst probably involve hydroxyl groups and $\mathrm{Fe}^{3+}$ ions. The decreases of the rate with high water pressure may reveal an equilibrium step with water as a product or a reverse step.

The oxido-reduction equilibration of the reaction shows that two $\mathrm{Fe}^{3+}$ ions must be reduced to $\mathrm{Fe}^{2+}$ to form one methacrylic acid molecule. Taking into account all these facts, the formal kinetic scheme shown in Fig. 6 is 


$$
\begin{aligned}
& \mathrm{O}^{2-}+\mathrm{H}_{2} \mathrm{O} \stackrel{\mathrm{K}_{0}}{=} 2 \mathrm{OH}^{-}
\end{aligned}
$$

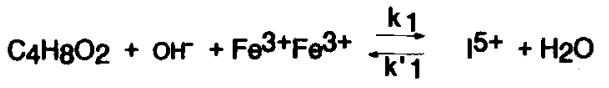

$$
\begin{aligned}
& \mathrm{I}++\mathrm{OH}^{-} \stackrel{\mathrm{K}_{2}}{\rightleftharpoons} \quad \mathrm{C}_{4} \mathrm{H}_{6} \mathrm{O}_{2}+\mathrm{H}_{2} \mathrm{O}+\mathrm{Fe}^{2}+\mathrm{Fe}^{2+} \\
& K_{2}=\frac{\mathrm{PH}_{2} \mathrm{O} \mathrm{PC}_{4 \mathrm{H}_{6} \mathrm{O}_{2} \theta_{t}}}{\theta_{1} \theta_{\mathrm{OH}^{-}}}
\end{aligned}
$$

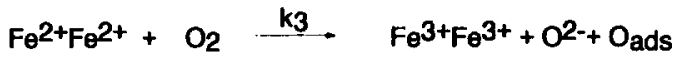

$$
\begin{aligned}
& V_{3}=k_{3} \theta_{r} P_{2} \\
& \mathrm{Fe}^{2+} \mathrm{Fe}^{2+}+\mathrm{Oads} \longrightarrow \mathrm{Fe}^{3+} \mathrm{Fe}^{3+}+\mathrm{O}^{2-} \\
& \text { and } \\
& \text { with } \\
& \mathrm{VC}_{4} \mathrm{H}_{6} \mathrm{O}_{2}=\frac{\mathrm{Mk}_{3} \mathrm{PC}_{4} \mathrm{H}_{8} \mathrm{O}_{2} \mathrm{PH}_{2} \mathrm{O}^{1 / 2} \mathrm{PO}_{2}}{\mathrm{MPC}_{4} \mathrm{H}_{8} \mathrm{O}_{2} \mathrm{PH}_{2} \mathrm{O}^{1 / 2+}+\mathrm{k}_{3} \mathrm{PO}_{2}+\mathrm{LPH}_{2} \mathrm{O}^{3 / 2} \mathrm{PC}_{4} \mathrm{H}_{6} \mathrm{O}_{2}} \\
& M=k_{1} \sqrt{K_{0}} \quad L=\frac{k^{\prime} 1}{K_{2} \sqrt{K_{0}}} \quad M L=\frac{k_{1} k_{1}^{\prime}}{K_{2}} \\
& \mathrm{~K}_{\mathrm{O}}=\frac{{ }^{\theta} \mathrm{OH}^{-}}{\mathrm{PH}_{2} \mathrm{O}} \\
& V_{1}=k_{1} \theta_{0} \theta O H-P_{4} H_{8} O_{2}-k_{1}{ }_{1} \theta P_{H_{2}} \mathrm{O}
\end{aligned}
$$

Fig. 6. Formal scheme and kinetic equations. The coverages are $\Theta_{\mathrm{OH}}$ for hydroxyls $\Theta_{0}$ for $\mathrm{Fe}^{3+} \mathrm{Fe}^{3+}, \Theta_{1}$ for the $\mathrm{I}^{5+}$ intermediate, $\Theta_{\mathrm{r}}$ for $\mathrm{Fe}^{2+} \mathrm{Fe}^{2+}$.

proposed. There is no difficulty in establishing the rate expression (Fig. 6) with the hypothesis that the superficial concentration $\Theta_{0}+\Theta_{\mathrm{r}}=1$. No simplification of this rate expression could be found if a good fit is to be obtained with the experimental data, particularly with the shape of the curve exhibiting a maximum as a function of water pressure.

\section{Constant determination}

The proposed rate expression shows that the rate depends on three independent constants, namely $M\left(M=k_{1} \sqrt{K_{0}}\right), L\left(L=k^{\prime}{ }_{1} / K_{2} \sqrt{K_{0}}\right)$ and $k_{3}$ (Fig. $6)$. It is not possible to determine the five basic kinetic constants $K_{0}, k_{1}$, $k^{\prime}{ }_{1}, K_{2}$ and $k_{3}$ by kinetic measurements alone.

The three independent constants $M, L$ and $k_{3}$ are determined by nonlinear regression, using a simplex method with the experimental data shown in Fig. 4; the values obtained are given in Table 4.

It is noteworthy that the $k_{3}$ constant which characterizes the catalyst reoxidation changes strongly with the catalyst. The minimum value of $k_{3}$ is obtained with $\mathrm{Fe}_{2} \mathrm{PO}_{5} \mathrm{~b}$, which exhibits the best electronic conductivity and ability for facile electron exchange [12]. In this case the whole crystal could be somewhat reduced but not deeply. Superficial sites may then activate a rapid oxidation by oxygen.

$\mathrm{Fe}_{2} \mathrm{P}_{2} \mathrm{O}_{7}$ contains only $\mathrm{Fe}^{2+}$ ions and could not be easily reduced further. This phase may be considered as the support for an oxidized phase which seems very active with oxygen. The $\mathrm{Fe}_{2} \mathrm{P}_{2} \mathrm{O}_{7}$ phase is an insulator, so the 


\section{TABLE 4}

Kinetic constants determined from Fig. 4; data fitted to the mechanistics scheme shown in Fig. 6

\begin{tabular}{llrll}
\hline Sample & $M=k_{1} \sqrt{\mathrm{K}_{0}}$ & \multicolumn{1}{c}{$k_{3}$} & $\mathrm{~L}=k^{\prime}{ }_{1} /\left(K_{2} \sqrt{K_{0}}\right)$ & $M L=k_{1} k^{\prime}{ }_{1} / K_{2}$ \\
\hline $\mathrm{Fe}_{2} \mathrm{P}_{2} \mathrm{O}_{7}$ & 0.35 & 325 & 0.100 & 0.035 \\
$\mathrm{Fe}_{2} \mathrm{PO}_{5} \mathrm{~b}$ & 0.40 & 9 & 0.004 & 0.0016 \\
$\mathrm{Fe}_{7}\left(\mathrm{PO}_{4}\right)_{8}$ & 1.20 & 73 & 0.250 & 0.3 \\
$\mathrm{FePO}_{4}$ & 2.30 & 62 & 0.025 & 0.058 \\
Ind. cat. & 4.65 & 72 & 0.070 & 0.325 \\
\hline
\end{tabular}

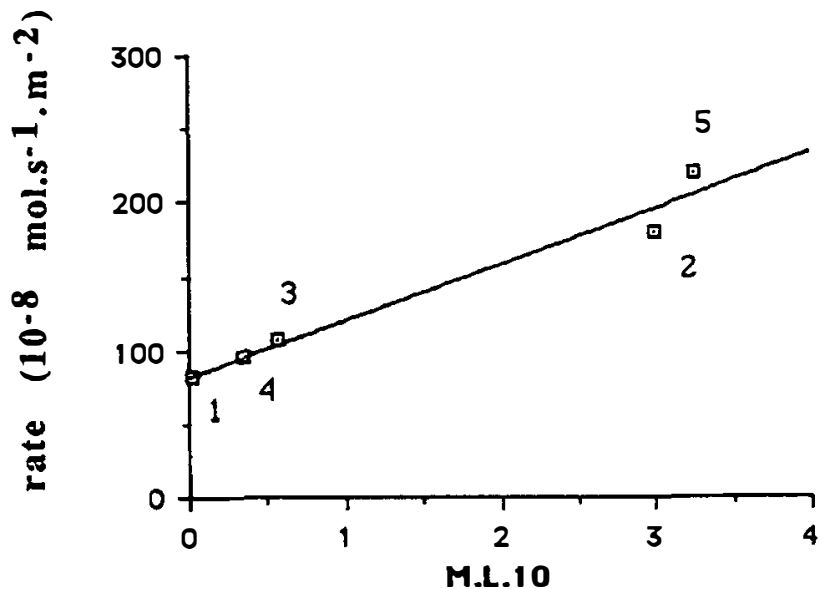

Fig. 7. Methacrylic acid reaction rate vs. $M L$ values for various catalysts: (1) $\mathrm{Fe}_{2} \mathrm{PO}_{5} \mathrm{~b}$, (2) $\mathrm{Fe}_{7}\left(\mathrm{PO}_{4}\right)_{6}$; (3) $\mathrm{FePO}_{4}$; (4) $\mathrm{Fe}_{2} \mathrm{P}_{2} \mathrm{O}_{7}$; (5) Ind. cat.

superficial sites remain very active and exhibit a large $k_{3}$ value. The amount of surface-oxidized phase may be estimated by the transient kinetics and turns out to be very large (Table 3 ).

The discussion on $M$ and $L$ values is more difficult because these constants have no physical meaning. The values of the kinetic constants (Table 4) could be discussed in terms of the properties of the solids.

The constant $M$ is the product of the $k_{1}$ constant of the supposed slow reduction step with the square root of $K_{0}$, the water ionisation equilibrium constant. For an efficient catalyst these two constants must be large, i.e. their product $M$ must also be large. A good catalyst should also have a small $k^{\prime}{ }_{1}$ and a large $K_{2}$ constant, which leads to a small $L$ constant.

No correlation appears between the catalyst activity and the values of $k_{3}, M$ or $M / L$, which, as shown by the kinetic equations, must all be large to result in high rates. On the contrary, the product $M L=k_{1} k^{\prime}{ }_{1} / K_{2}$ was found to correlate well with the catalytic activity, as shown in Fig. 7 . The $k^{\prime}{ }_{1} / K_{2}$ ratio is expected not to change very much with $\mathrm{I}^{5+}$ stability, which suggests that the $k_{1}$ constant may change significantly with the catalyst nature and 
could vary as the $M L$ values. With such a hypothesis one may conclude that the industrial catalyst is the most active sample in forming the $\mathrm{I}^{5+}$ intermediate and that more efficient catalysts may be hopefully prepared, since the maximum $L$ and $M$ values were not obtained for the same catalyst (Table 4).

\section{Discussion}

A good fit has been obtained between the model proposed and the kinetic results. It is however necessary to determine whether this model agrees with the chemical properties of the various solids, or if a possible chemical mechanism could support this model.

The interaction of an isobutyric acid molecule with a surface $\mathrm{Fe}^{3+}$ ion may involve the oxygen atom, which corresponds to the nucleophilic part of the molecule. Reduction with the formation of a first water molecule could be due to a cyclic concerted electron transfer starting from the nucleophilic surface hydroxyl group to one of the hydrogen atoms of the isobutyric acid molecule, creating a double bond in the molecule and opening the $\mathrm{C}-\mathrm{O}$ bond to a $\mathrm{C}-\mathrm{O}-\mathrm{Fe}$ bond. Thus the intermediate species $\mathrm{I}^{5+}$ at the catalyst surface could be an iron alkoxide, as schematized in Fig. 6 .

Various reaction routes could be described involving different hydrogen atoms susceptible to react with the first hydroxyl groups (Fig. 8, routes $2 \mathrm{a}$, $2 b, 2 c)$. The first and most probable is the reaction of the surface hydroxyl groups with the $\mathrm{H}$ atom adjacent to the $\mathrm{C}=\mathrm{O}$ bond (Fig. 8, 2a). A second possibility is the attack of the acidic hydrogen of a superficial isobutyrate (Fig. 8, 2c). A third way, corresponding to initial reaction of the hydroxyl group with the methyl hydrogen, seems less probable.

In this first step the surface ferric ion is reduced to $\mathrm{Fe}^{2+}$. However, as the solids are both electronic and ionic conductors, it is possible that this surface ion remains at the $3^{+}$oxidation state and that another cation is reduced to $2^{+}$. Such an equilibrium between $\mathrm{Fe}^{2+}$ and $\mathrm{Fe}^{3+}$ would permit a second cyclic concerted electron transfer to produce the second water molecule and liberate the product from the catalytic surface.

In the $2 \mathrm{a}$ case, reaction of the hydroxyl with a methyl hydrogen gives the methacrylic acid molecule. In the $2 \mathrm{c}$ case, the same reaction gives propene and $\mathrm{CO}_{2}$ molecules. This could explain the formation of the propene product.

The route to propene proposed in several studies on other types of catalyst involves acidic decomposition of isobutyric acid, i.e. the reverse of the propene carbonylation reaction $[3,22]$ :

$\left(\mathrm{CH}_{3}\right)_{2}-\mathrm{CH}-\mathrm{COOH} \longrightarrow \mathrm{CH}_{3}-\mathrm{CH}=\mathrm{CH}_{2}+\mathrm{CO}+\mathrm{H}_{2} \mathrm{O}$

It is interesting at this point to note that the study of the oxidative dehydrogenation of isobutyric acid on VPO catalyst has been studied and that propene was the main byproduct on these catalysts [3]. Moreover, propene selectivity has been shown to increase with the $P / V$ ratio of the catalysts. It is known that the acidity of these solids increases when the 


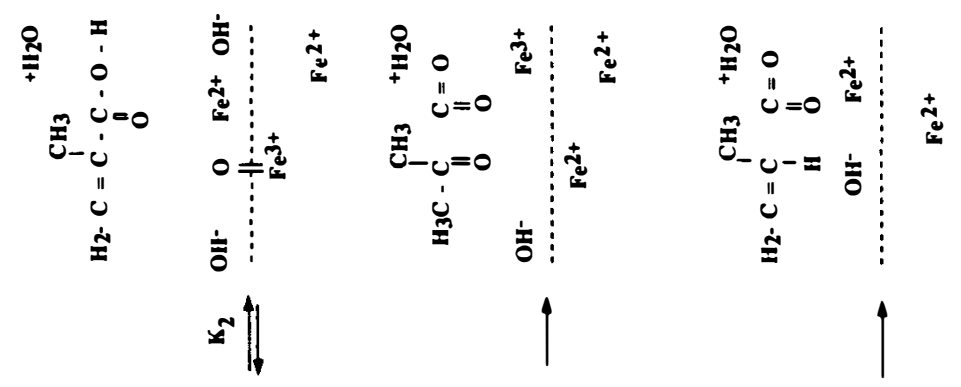

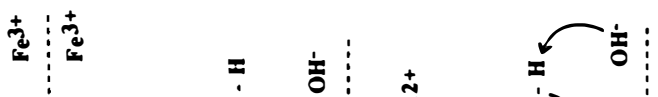

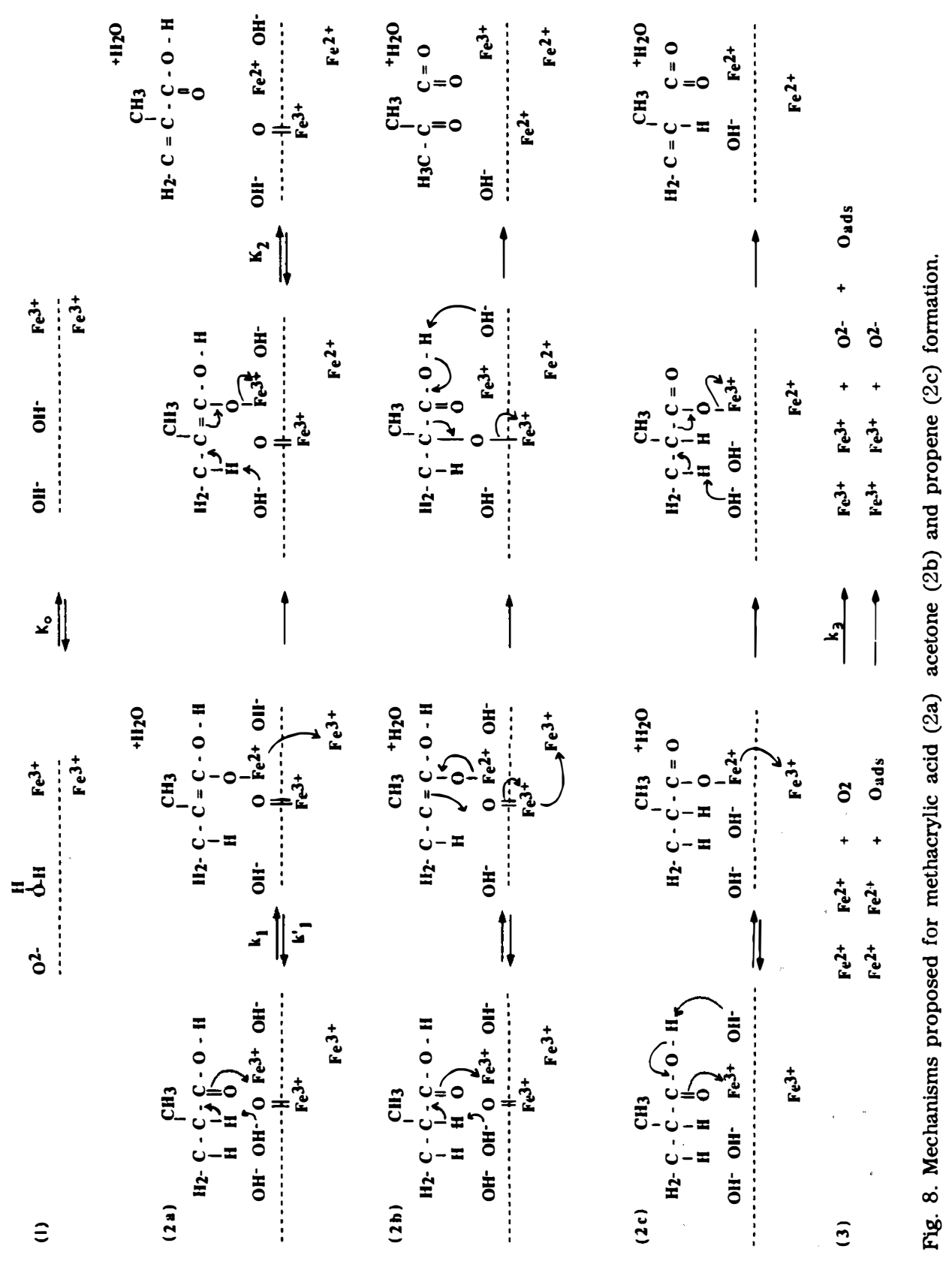


$P / V$ ratio increases. Such an observation should lead us to favour this interpretation.

However in our reaction conditions, formation of $\mathrm{CO}$ was not observed. This supports the mechanism of propene formation described above (Fig. $8,2 \mathrm{c})$. The propene formation could be favoured on solids which exhibit (i), a more labile acidic hydrogen, (ii) too great a distance between hydroxyls and $\mathrm{Fe}^{3+}$ cations to allow reaction with the allylic hydrogen to take place, (iii) fewer hydroxyl groups at the surface. The latter case is supported by the observation that propene selectivity is higher at low water pressure.

If the oxide surface contains oxygen ions not transformed into hydroxyls, they could interact with the carbon atom adjacent to the $\mathrm{C}-\mathrm{O}-\mathrm{Fe}$ bond of the adsorbed intermediate and contribute another bond to the surface (Fig. $8,2 b)$. In such a case there exists a second cyclic concerted electronic transfer, and acetone and $\mathrm{CO}_{2}$ are formed. This explains how acetone yield increases when water pressure decreases and confirms that acetone is favoured on solids containing more labile oxygens (Table 2).

\section{Acknowledgements}

Dr. C. Gleitzer is gratefully acknowledged for supplying several samples studied in the present work and for fruitful discussions.

\section{References}

1 U.S. Pat. 3948959 (1976) to E. Cavatera, Montedison.

2 U.S. Pat. 4298755 (1981) to C. Daniel, Ashland Oil Inc.

3 M. Ai, J. Catal., 98 (1986) 401.

4 M. Akimoto, K. Shima, H. Ikeda and E. Echigoya, J. Catal., 86 (1984) 173.

5 V. Ernst, Y. Barbeau and P. Courtine, Catal. Today, 1 (1987) 167.

6 J. C. Kaell, F. Jannot and C. Gleitzer, Ann. Chim., 9 (1984) 169.

7 A. Modaressi, J. C. Kaell, B. Malaman, R. Gerardin and C. Gleitzer, Mater. Res. Bulh, 18 (1983) 101.

8 A. Modaressi, A. Courtois, R. Gerardin, B. Malaman and C. Gleitzer, J. Solid State Chem., 47 (1983) 245.

9 A. Modaressi, A. Courtois, R. Gerardin, B. Malaman and C. Gleitzer, J. Solid State Chem., 40 (1981) 301.

10 M. Bouchoug, A. Courtois, R. Gerardin, J. Steinmetz and C. Gleitzer, J. Solid State Chem., 42 (1982) 49.

11 R. Venturi, A. Courtois, J. Steinmetz, R. Gerardin and C. Gleitzer, J. Solid State Chem., 53 (1984) 1.

12 B. Ech-Chaed, F. Jeannot, B. Malaman and C. Gleitzer, J. Solid State Chem., 74 (1988) 47.

13 M. Forissier, D. Foujols, A. Modaressi and C. Gleitzer, Bull. Soc. Chim. Fr., I (1985) 410.

14 E. G. Vrieland, J. Catal., 111 (1988) 1.

15 A. V. Annapragada and E. Gulari, J. Catal., 123 (1990) 130.

16 C. Virely, O. Fafregue and M. Forissier, Bull. Soc. Chim. Fr., I (1988) 457.

17 J. M. M. Millet, C. Virely, M. Forissier, P. Bussière and J. C. Védrine; Hyperfine Interact., 46 (1989) 619. 
18 U.S. Pat. 4410727 (1983) to F. Ruszala, Ashland Oil Inc.

19 M. Forissier, D. Foujols, C. Lesselbaum and J. L. Portefaix, Bull. Soc. Chim. Fr., I (1985) 1195.

20 D. Carson, M. Forissier and J. C. Védrine, Chem. Soc. Faraday Trans. I, 80 (1984) 1017.

21 P. Mars and D. W. Krevelen, Chem. Eng. Sci., Suppl, 3 (1954) 41.

22 Gaucher, Thesis, Compiègne, France, 1984.

23 M. Otake and T. Onada, J. Catal, 38 (1975) 494. 